\title{
Challenges when evaluating Product/Service-Systems through Life Cycle Assessment
}

Kjær, Louise Laumann; Pagoropoulos, Aris; Schmidt, Jannick H.; McAloone, Tim C.

Published in:

Journal of Cleaner Production

Link to article, DOI:

10.1016/j.jclepro.2016.01.048

Publication date:

2016

Document Version

Peer reviewed version

Link back to DTU Orbit

Citation (APA):

Kjær, L. L., Pagoropoulos, A., Schmidt, J. H., \& McAloone, T. C. (2016). Challenges when evaluating Product/Service-Systems through Life Cycle Assessment. Journal of Cleaner Production, 120, 95-104. https://doi.org/10.1016/j.jclepro.2016.01.048

\section{General rights}

Copyright and moral rights for the publications made accessible in the public portal are retained by the authors and/or other copyright owners and it is a condition of accessing publications that users recognise and abide by the legal requirements associated with these rights.

- Users may download and print one copy of any publication from the public portal for the purpose of private study or research.

- You may not further distribute the material or use it for any profit-making activity or commercial gain

- You may freely distribute the URL identifying the publication in the public portal

If you believe that this document breaches copyright please contact us providing details, and we will remove access to the work immediately and investigate your claim 
Article for Journal of Cleaner Production

Word count: 10749 (10394 without title page and abstract. 8441 without references)

Title: Challenges when Evaluating Product/Service-Systems through Life Cycle Assessment

Authors: Louise Laumann Kjaer ${ }^{1}$, Aris Pagoropoulos ${ }^{1}$, Jannick H. Schmidt ${ }^{2}$, Tim C. McAloone 1

1 Technical University of Denmark, Department of Mechanical Engineering, Nils Koppels Allé, Building 426, 2800 Kgs. Lyngby, Denmark. E-mails: 1lkj@mek.dtu.dk, arispa@mek.dtu.dk, tmca@dtu.dk

2 Aalborg University, Department of Development and Planning, Skibbrogade 5, 9000 Aalborg, Denmark. E-mail: jannick@plan.aau.dk

\section{Manuscript Correspondence:}

*Corresponding author:

Louise Laumann Kjaer

Address: Nils Koppels Allé, Building 426

Email: $\underline{1 \mathrm{kj} @ m e k . d t u . d k}$

Telephone: +45 26172687 


\begin{abstract}
Life Cycle Assessment (LCA) is a state-of-the art method for conducting environmental assessments of systems, whether these consist of goods or services, or a combination of the two. However, current LCA guidelines focus on assessing tangible products and lack specific attention to more complex systems, such as Product/Service-Systems (PSS), which also consist of intangible elements. PSS imply a shift in business paradigm from selling specific products to delivering a function, through a mix of products and services, thereby incentivising resource efficiency as well as user satisfaction. Despite their potential to reduce environmental impacts, PSS are not by default more environmentally benign compared to conventional systems, and quantifications of their environmental performance are called for. This paper contributes by showing that specific challenges need to be addressed when using LCA to evaluate the environmental performance of PSS. We identify a set of PSS characteristics that can challenge an LCA study. Three relevant scopes are distinguished, where LCA may be applied: (1) evaluating options within the PSS itself; (2) comparing a PSS with an alternative; and (3) modelling the actual contextual changes caused by the PSS. We derive three pronounced challenges when conducting LCA within the three scopes: (i) identifying and defining the reference system; (ii) defining the functional unit; and (iii) setting system boundaries. We elaborate on how these challenges are discussed in current literature. Recommended future work includes developing adapted guidelines and further empirical case studies that quantify the environmental changes and impacts caused by introducing PSS.
\end{abstract}

Keywords: Life Cycle Assessment, Product/Service-Systems, environmental impacts, reference system, functional unit, system boundaries 


\section{Introduction}

Life Cycle Assessment (LCA) is a method for evaluating the environmental performance of products. According to the ISO14040:2006 standard on LCA, a product may be defined as any good or service (ISO, 2006a). The methodological steps are therefore considered the same, whether the function is fulfilled through the delivery of a physical product or an intangible service. This definition implicitly makes the method suitable for environmental evaluation of what is commonly referred to as Product/Service-Systems (PSS).

PSS promote a focus shift from selling just products to selling the utility, through a mix of products and services while fulfilling the same client demands with less environmental impact (Manzini and Vezzoli, 2002). In developing and offering PSS, companies move from traditional manufacturing-based product-sale business models towards delivering a desired function. A PSS can thus be seen as the result of a strategy that seeks to optimize the performance of a system through supporting users and other stakeholders in the post-production life cycle stages.

This seems well in line with LCA, which also promotes the search for improvement potentials throughout entire life cycles and in this way sets the frame to encourage thinking in systems rather than in single-product solutions; all this while basing on a methodological framework that is fully in place (Bey and McAloone, 2006). However, as will be shown in this article, using LCA to evaluate the environmental performance of PSS can be challenging. While the methodological framework in LCA is considered the same for products and services, the PSS concept pays greater attention to the difference between tangible products (such as machinery), and intangible services and activities (such as maintenance), as it is their integration that brings value and creates the "system” (Baines et al., 2007). In this sense, PSS is seen as more than a combined set of product and service inputs. It is a result of a design strategy based on new systems of values and innovative market opportunities (Manzini and Vezzoli, 2003). In their Multilevel Design Model, Joore and Brezet (2014) place PSS as the connection between the product-technology system and socio-technical system, illustrating the PSS’ position in translating societal needs into novel solutions.

PSS is widely claimed to have the potential to reduce environmental impacts whilst maintaining, transforming, or even adding to user satisfaction (Salazar et al., 2014). It has even been suggested as a possible cure to obese consumption patterns (Kang and Wimmer, 2008). Nevertheless, it is also recognised that PSS solutions do not by default lower environmental impacts (Tukker and Tischner, 2006). Therefore, quantifications of the claimed benefits from PSS are called for (Beuren et al., 2013; Tukker, 2013). Being a method for environmental evaluation, LCA should be helpful in this regard. However, LCA is typically applied on single product systems, where the functions are provided by tangible elements and current guidelines illustrate the method through simple examples (such as an office chair (Weidema et al., 2004)) or by comparing two types of products (e.g. wall paints (European Commission, 2010)). Even though cases exist, where the LCA methodology is also used for systems that go beyond a single product system (e.g. sites, raw material strategies, mobility solutions (European Commission, 2010 p 33)), LCA guidelines do not explicitly state how assessments of these more complex systems might be different or should be handled. In these cases it is questioned, whether the analysis can be claimed to be an LCA. As stated in the review by Finnveden et al. (2009): "With a more narrow interpretation of the LCA concept, where an LCA is a study of one product's life cycle only, it may be argued that a study that is using expanded system boundaries, giving it several functional units, should not be called an LCA at all. Instead such a study could be called an environmental systems analysis using LCA methodology”.

What is referred to here as a "narrow interpretation" perhaps explains the reason why LCA could be perceived as inadequate for PSS. One reason is that in comparative LCA, functional equivalence between the alternatives is required 
according to the ISO standard. In this sense, LCA is considered best suited for product- or "micro" level assessments (Klöpffer, 2014), while PSS often implies changing the existing socio-technical system (the "meso"-level) (Joore and Brezet, 2014; Vezzoli et al., 2015) and introduces the user to rather different intangible values such as 'priceless' experiences, brand value, sense of control, ease of access, etc. (Tukker, 2013). Therefore, it has been argued that for PSS, the application of LCA according to the ISO standard (ISO, 2006a) (ISO, 2006b) is not always possible, since one needs to compare systems that do not have the exact same functionality (Brezet et al., 2001; Salazar et al., 2014).

The methodological issues and challenges specific to PSS are currently not explicit in core LCA literature (what is here referred to as core literature will be elaborated in section 2) and no specific guidelines for assessing the environmental performance of PSS exist. Such guidelines would be beneficial for researchers and practitioners, both in the PSS and LCA communities, in their effort to evaluate the environmental performance of PSS. This article seeks to take the first step in filling this gap by answering the following research question: Which challenges might occur when using LCA to evaluate the environmental performance of PSS? We identify a set of PSS characteristics that might challenge an LCA and derive three challenges mainly related to the goal and scoping phase of the LCA process. We provide suggestions to how they might be overcome based on current literature and highlight further work needed. The aim is to assist PSS and LCA researchers in formulating approaches and guidelines for environmental evaluation of PSS.

The paper is structured as follows. The next section describes the research method. Section 3 introduces the PSS concept and the identified characteristics. In section 4 , we present and discuss the derived challenges and in section 5 , we translate the identified challenges into some overall recommendations and state future work needed.

\section{Research method}

The research method consisted of a systematic literature review combined with expert consultations. The systematic literature review followed an aprioristically developed protocol (Biolchini et al., 2005). The aim of the review was to identify cases of LCA on PSS and how potential challenges were discussed in current publications within the environmental field of PSS. A search on "environmental quantification of PSS" and related synonyms was conducted in Scopus, Web of Science and Science Direct, in order to identify relevant journal articles. Analyses of citations and screenings of LCA conference proceedings were performed to expand to so-called 'grey literature' (reports and literature not formally published) and conference papers. A total of 75 publications were reviewed. However, from year 2000 to 2015 only 11 journal articles were found to present PSS cases that assessed the use of LCA or similar approaches (such as simplified or 'streamlined' LCA). The limited number of case studies gave a clear indication that the experience within the scientific community on conducting LCA on PSS was limited. Even though the search revealed a larger number of conceptual papers discussing environmental aspects and the concept of PSS, only a few of these publications discussed the use of LCA explicitly.

We therefore took a process-based approach to answer the research question, which is illustrated in Figure 1. Based on core LCA literature (presented in Table 1), we identified the steps and general challenges when conducting an LCA. Building on this, from the PSS literature, we identified a set of PSS characteristics that might challenge an LCA. 


\begin{tabular}{|c|c|c|}
\hline Publication type & Title & Reference \\
\hline \multirow[t]{2}{*}{ ISO standards } & ISO 14040 & (ISO, 2006a) \\
\hline & ISO 14044 & (ISO, 2006b) \\
\hline \multirow[t]{4}{*}{ Guidelines } & $\begin{array}{l}\text { International Reference Life Cycle Data System (ILCD) } \\
\text { Handbook }\end{array}$ & (European Commission, 2010) \\
\hline & Market information in life cycle assessment & (Weidema, 2003) \\
\hline & $\begin{array}{l}\text { The Product, Functional Unit and Reference Flows in } \\
\text { LCA }\end{array}$ & (Weidema et al., 2004) \\
\hline & $\begin{array}{l}\text { Guidelines for application of deepened and broadened } \\
\text { LCA }\end{array}$ & (Weidema et al., 2009) \\
\hline \multirow[t]{3}{*}{ Review- and methodology papers } & $\begin{array}{l}\text { Life cycle assessment Part 1: Framework, goal and scope } \\
\text { definition, inventory analysis, and applications } \\
\text { Recent developments in Life Cycle Assessment. }\end{array}$ & $\begin{array}{l}\text { (Rebitzer et al., 2004) } \\
\text { (Finnveden et al., 2009) }\end{array}$ \\
\hline & $\begin{array}{l}\text { A survey of unresolved problems in life cycle } \\
\text { assessment. Part 1: Goal and scope and inventory } \\
\text { analysis }\end{array}$ & (Reap et al., 2008) \\
\hline & $\begin{array}{l}\text { System Boundaries and Input Data in Consequential Life } \\
\text { Cycle Inventory Analysis }\end{array}$ & (Ekvall and Weidema, 2004) \\
\hline
\end{tabular}

Table 1: Core LCA literature consulted in the process

The identified case studies from the literature review showed that different scopes can be applied when evaluating the environmental performance of PSS. We therefore derived three different study scopes (presented in section 4) and related the identified challenges to these.

Five PSS experts were consulted to verify PSS characteristics and five LCA experts were interviewed to confirm and discuss the identified scopes and challenges. The PSS expert consultation consisted of presenting and discussing the characteristics through short semi-structured interviews, some of which were followed up by e-mail correspondence. The experts were all active, publishing researchers and had minimum five years of experience within the field of PSS. The LCA expert consultation consisted of semi-structured interviews during individual two hour sessions, where the PSS concept was presented and LCA-related challenges discussed. The identified case studies from the literature review were used to exemplify the challenges. All LCA experts were active, publishing researchers with minimum ten years of experience within LCA.

To sum up, the challenges presented in this paper were derived based on LCA literature, PSS characteristics, analyses of the identified case studies and expert consultation. 


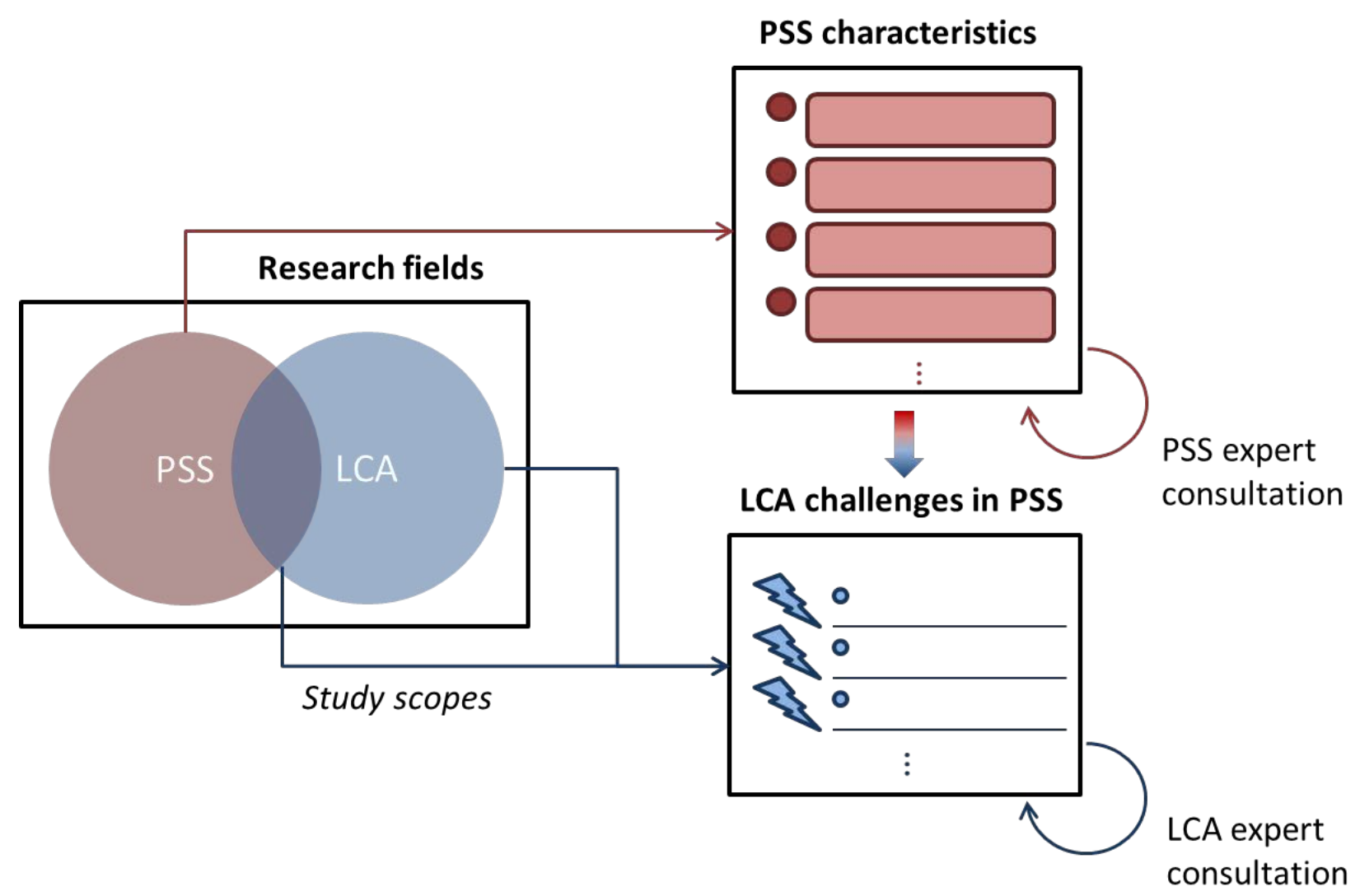

Figure 1: The proces of deriving the challenges

\section{The PSS concept and its characteristics}

In this section we introduce the PSS concept and a set of characteristics, which might influence an environmental evaluation using LCA as a method.

A number of PSS definitions have been proposed over the years (Tukker, 2013), which essentially refer to "product(s) and service(s) combined in a system to deliver required user functionality” (Baines et al., 2007). Mont (2004b) assigned four properties to a PSS (i-iv), by defining it as “(i) a system of products, services, networks of actors and supporting infrastructure that continuously strives to be (ii) competitive, (iii) satisfy customer needs and (iv) have a lower environmental impact than traditional business models”. Property (iv) supports the importance of quantification, as it suggests that reduction in environmental impacts is a qualifying characteristic for a system, in order to be considered a PSS.

As the literature field expanded over the years, PSS literature started focusing more on new business development and improving competitiveness and less on sustainability, which has led to definitions leaving out the environmental dimension (Tukker, 2013). In more recent literature, when PSS adds environmental considerations they are often labelled eco-efficient PSS (Ceschin, 2013) or sustainable PSS (SPSS) (Gelbmann and Hammerl, 2014; Vezzoli et al., 2015). These are the type of PSS of interest in the context of this paper, since they employ environmental strategies, and it is the potential effect of those that will be evaluated through the use of LCA. 
PSS are commonly classified into three categories (Beuren et al., 2013; Bocken et al., 2014; Tukker, 2004; Wang et al., 2011): 1) product-oriented, e.g. after-sale services such as maintenance and consultancy; 2) use-oriented e.g. car-sharing or carpet leasing; and 3) result-oriented e.g. "pay-per-use”, energy management services, or chemical management services.

In all three types of PSS, the responsibility of the provider extends to cover elements in the "after gate” life cycle stages, such as the use stage and end-of-life (Baines et al., 2007; Evans et al., 2007). The sustainability philosophy is that moving profit centres away from the physical products towards the result delivered incentivise the provider to adopt strategies that will make the offering environmental benign, primarily through dematerialisation.

For product-oriented PSS, the provider might implement environmental strategies such as:

- $\quad$ Supporting the efficient use of the product, which is e.g. relevant for energy-using products (Tan and McAloone, 2006).

- $\quad$ Extending the useful lifetime of the product (Hirschl et al., 2003).

- $\quad$ Reducing waste and optimizing end-of-life treatment through take-back systems (Baines et al., 2007; Kerr and Ryan, 2001).

For use-oriented and result-oriented PSS these strategies might be extended to also benefit from the fact that the provider retains ownership of the products. This opens up for additional strategies such as:

- Increased product utilisation through joint use (Mont, 2004a).

- $\quad$ Easier promotion of clean technology implementation due to reduced down payment (Shih and Chou, 2011; Vezzoli et al., 2015).

- Demand-side/activity management that aims at reducing resource consumption such as energy service company (ESCO) agreements and material efficiency services including chemical management services (Anttonen et al., 2013).

Despite the promise of these strategies, the success of PSS and their ability to reduce environmental impacts is not guaranteed. Successful implementation depends on user acceptance, contextual dependencies and potentially induced rebound effects. Moreover, for the PSS provider a series of success factors need to be in place such as partnership networks and strategic stakeholder interactions (Vezzoli et al., 2015). All in all, we have identified seven characteristics of the PSS concept, which might challenge an LCA. These are presented in Table 2. Many types of PSS exist, differentiating both in terms of the extent of changes they introduce (ranging from incremental to radical), complexity (amount of flows and inputs) and environmental strategy (e.g. if different end-of-life options are considered). Thus, not all characteristics will apply to all PSS. How profound the characteristics are and thus how they influence an LCA will be highly case dependent.

In the next section we elaborate on the identified implications and how it can challenge an LCA study.

\begin{tabular}{ll}
\hline Author(s) & Quote \\
\hline (CH1) Enables innovation & “Equal focus on product and service development can enable innovations and therefore product and service \\
(Meier et al., 2010) & "A product service system (PSS) can be defined as 'an innovation strategy, shifting the business focus from \\
(Manzini and Vezzoli, 2003) & are jointly capable of fulfilling specific client demands” (and selling) physical products only, to designing (and selling) a system of products and services which \\
& "PSSs are in most of the cases radical innovations, because they challenge existing customers’ habits (cultural \\
barriers), companies’ organizations (corporate barriers) and regulative frameworks (regulative barriers)”
\end{tabular}




\section{(CH2) Affects and relies on user behaviour and perceptions}

(Tukker, 2013)

(Mont, 2004b, p. 116)

(Goedkoop et al., 1999)

\section{(CH3) Is context dependent}

(Manzini and Vezzoli, 2003)

(Joore and Brezet, 2014)

(Rexfelt and Ornäs, 2009)
"PSS usually do not allow consumers as much behavioural freedom or even leave them with the impression that the PSS provider could prescribe how they should behave"

“The environmental impacts of [business to consumer] B2C PSSs depend to a large extent on user behaviour"

"When we want to compare the situation before and after the introduction of the PS system, we must be aware of the fact that the consumer behaviour will probably change"

"PSS ... rely on existing technologies and socio-cultural context”

"Product-service systems, accompanying infrastructure, government legislation and cultural as well as social aspects may form a mutually interdependent whole”

"The socio-cultural context in which the PSS is offered is an important factor for consumer acceptance"

(CH4) Is (often) a design strategy*

(Manzini and Vezzoli, 2003)

"PSS is the fruit of a (mostly unconscious) strategic design. In fact, with the term strategic design it is intended a design activity aiming at an integrated system of products, services and communication, based on new forms of organization, based on the roles reconfiguration of different companies, clients and other stakeholders; a design developing a strategy linking long term goals with existing trends and based on new systems of values and new market opportunities”

(Reim et al., 2014)

"In the literature on PSS business models, several case studies and conceptual papers highlight the importance of an adapted product and service design in which the entire life cycle of the product is considered”

(Evans et al., 2007)

“Through the problem-solving design task, the combination and interaction between different key material and immaterial elements enables actors to produce innovative product-service solutions at a system level and to offer therein an environmental and/or social improvement potential”

(CH5) Involves the whole product life cycle, often including end-of-life options thereby extending into multiple life cycles

(Baines et al., 2007)

"The company [provider] is motivated to introduce a PSS to minimize costs for a long-lasting, well-functioning product and to design products to take account of product end-of-life”

(Tukker, 2013)

“[In service oriented business models] firms will have an incentive to prolong the service life of products, to ensure they are used as intensively as possible, to make them as cost- and material-efficiently as possible, and to re-use parts as far as possible after the end of the product's life"

(Gelbmann and Hammerl, 2014)

“As typical of SPSS ... the notion "re-use” refers to extending the lifespan of commodities, aiming to close material loops and thereby increasing the eco-efficiency of material use and decreasing waste generation”

\section{(CH6) Is a system of tangible (product) and intangible (service) elements}

(Tukker and Tischner, 2006)

“A Product-Service System consists of tangible products and intangible services designed and combined so that they jointly are capable of fulfilling specific customers’ needs”

(Wang et al., 2011)

"PSS integrates tangible artefact and intangible service to achieve sustainability, improve enterprise competitiveness, and meet customer needs better”

\section{(CH7) Relies on a supporting background system}

(Reim et al., 2014)

"Providing services adds several new tasks to the operations of manufacturing or service companies. Because the companies cannot perform these tasks independently, they must develop networks and partnership infrastructures"

(Mont, 2004b, p. 110)

"Infrastructure is an important factor that may support or hinder new service- oriented solutions and PSSs"

(Brezet et al., 2001)

\section{Table 2: PSS characteristics}

\footnotetext{
* In principle LCA can be used both in the design process and as an evaluation tool. Our literature review revealed that PSS is seen as a design activity by the majority of the analysed case studies of LCA on PSS, with only a few papers demonstrating LCA on existing PSS offerings (e.g. Lindahl et al. 2014).
} 


\section{Challenges in LCA on PSS}

LCA follows four phases: 1) Goal and scope definition; 2) inventory analysis; 3) impact assessment; and 4) interpretation. Although presented in sequence with one phase feeding into the next, the LCA technique is iterative, in order to ensure comprehensiveness and consistency of the study (ISO, 2006b).

The first steps in the goal definition are to establish: the intended application; the reason to carry out the study; the intended audience; and whether the results are used in comparative assertions disclosed to the public. A key element in the goal definition is therefore whether or not the study is of comparative nature. However, ISO (2006b) does not give precise guidance on different scopes and how the LCA process might differ.

In the absence of a suitable distinction in current literature, we define three study scopes based on how the environmental performance of a PSS was evaluated in the identified case studies, see Table 3.

\begin{tabular}{|c|c|c|}
\hline Scope & Question addressed & Description and examples \\
\hline PSS optimization & $\begin{array}{l}\text { Which impacts are caused by the PSS and how to } \\
\text { optimise it? }\end{array}$ & $\begin{array}{l}\text { Investigating how to optimize a PSS designed to fulfil a certain } \\
\text { function (e.g. provide information), see e.g. Lelah et al. (2011) or } \\
\text { Salazar et al. (2014). Only variations within the PSS are assessed, } \\
\text { since the user perceived outcome is considered not to be altered. }\end{array}$ \\
\hline PSS comparison & $\begin{array}{l}\text { What are the environmental impacts of the PSS } \\
\text { compared to one or more alternatives that fulfil the } \\
\text { same function in a different manner? }\end{array}$ & $\begin{array}{l}\text { Comparing one or more pre-defined alternatives to the proposed } \\
\text { PSS. Examples include comparing home laundry with industrial } \\
\text { laundry (Haapala et al., 2008) or comparing a residential air } \\
\text { conditioning unit with a "conditioned air service" (Bennett and } \\
\text { Graedel, 2000). In these cases, the PSS is compared to an } \\
\text { alternative with a similar functional outcome. }\end{array}$ \\
\hline PSS consequences & $\begin{array}{l}\text { How do the environmental impacts of the system } \\
\text { change as a consequence of introducing a PSS? }\end{array}$ & $\begin{array}{l}\text { Evaluating how the PSS changes the contextual system and what } \\
\text { is being substituted by the PSS. Examples include assessing how } \\
\text { the need for transport and the need for different transport options } \\
\text { changes as a result of introducing a car-sharing scheme, see e.g. } \\
\text { Firnkorn et al. (2011). All relevant alternatives within the } \\
\text { contextual system influenced by the PSS are assessed, together } \\
\text { with changes in the user perceived outcome. }\end{array}$ \\
\hline
\end{tabular}

Table 3: Study scopes

The first study scope "PSS optimization" focuses on the PSS itself, in order to identify hotspots and evaluate different improvement options. This evaluation will be relevant both in designing a PSS to have an optimized environmental performance and in optimizing a current PSS offering without altering the user perceived result. This type of study cannot be used to argue that a PSS is more environmentally benign compared to an alternative solution, since it is not a comparative study by nature. However, when the objective of the PSS is to ensure a certain improvement such as energy, material or transport savings, this type of LCA study can assess if the environmental impacts caused by the PSS itself exceed the environmental gains or introduce trade-offs. An example of such a study is given in Lelah et al. (2011), where potential improvement of a Machine-to-Machine (M2M) enhanced PSS for waste glass collection is identified and the PSS induced impacts held up against the benefits from saved transportation.

The second study scope "PSS comparison" resembles a common LCA setup, where two or more systems fulfilling the same function are compared. An example is Lindahl et al. (2014) who present three cases of integrated product service offerings compared to their traditional business model.

While the "PSS comparison” is focused on evaluating two or more predefined alternatives, "PSS consequences" seeks to capture all relevant substitutes and evaluate to what extent they occur. Thus, "PSS consequences” tries to assess the actual consequences of implementing a PSS solution into a system and will be especially relevant for a PSS with a considerable 
number of substitutes, each of which create different levels of utility for the user, and which might complement each other in delivering a specific function. Even though not utilising a full LCA approach, Firnkorn et al. (2011) give such an example in evaluating the environmental effects of new free-floating car-sharing system in a city, and evaluate how car-sharing displaces public transportation and private car driving.

All three scopes have the purpose of evaluating the effect of a change. Which scope is relevant depends on the purpose of the assessment and is not to be confused with the modelling approach during the life cycle inventory (LCI) phase of an LCA. Here, typically two different modelling approaches are considered; the consequential and attributional approaches. The attributional approach is defined as a normative approach to modelling (Sonnemann and Vigon, 2011, p. 132) and byproducts are often modelled using allocation. In contrast, the consequential approach is a cause-effect based approach (Sonnemann and Vigon, 2011, p. 133), and by-products are handled using system expansion. It cannot be argued that the choice between the two approaches and the challenges involved in this regard is any different for PSS than for other systems analysed through LCA.

We have identified three overall challenges relevant for LCA on PSS. In regards to the phases in LCA they are all closely related to the goal and scope definition, but will influence the subsequent phases of the LCA process. The challenges are presented in the following sections, where we explain them from an LCA perspective, link the identified PSS characteristics to each of them, and discuss how the challenge might differ according to the study scope selected.

\subsection{Reference system}

This section deals with defining the reference system to which the PSS is compared. While a baseline can be seen as the situation without the new or optimized PSS, we define the reference system as the framed scenario(s) to which the PSS is compared. In LCA terminology this is also referred to as the comparable alternatives, which deals with identifying the relevant substitutions for the system under analysis (Weidema et al., 2004). Identifying the relevant substitutions is a core task in all LCA studies with the purpose of evaluating the effect of introducing a new product or service to the market (Weidema et al., 2004). For PSS, the challenge is even more pronounced. The fact that PSS enables innovation and novelty in the way needs are fulfilled ( $\mathrm{CH} 1)$, and is often seen as a design strategy ( $\mathrm{CH} 4)$ adds to the uncertainty of specifying the correct reference system, since the assessment will often be done ex-ante - before implementation - when there is no data on how the market has changed as a consequence of introducing the PSS.

The fact that PSS often rely on behavioural changes (CH2) and other contextual factors (CH3) to support a successful implementation means that assumptions regarding these factors need to be made. Notice that PSS are not necessarily more uncertain, compared to the "non-PSS" alternative. For a result-oriented PSS such as "refrigeration service" (Tan et al., 2010) the provider of the solution retains control over the refrigeration components and systems. In this way the provider ensures the delivery of a result, thus reducing uncertainties that arise from e.g. unexpected breakdowns or improper use. In stark contrast, uncertainties can be higher for use-oriented PSS, where the solution is provided as a platform for users, but the provider has no or limited control over which users decide to use the system or how they behave. A bike-sharing system is an example of a use-oriented PSS where there is not one single alternative to the shared bike in the eye of the user. It fact, the bike-sharing system could substitute many transport means such as public transportation, own bike, rented bike, and walking. It might also increase the need for transport, e.g. when used by tourists to explore a city (Büttner et al., 2011). Comparing the bike-sharing system to an owned bike as demonstrated by Amaya et al. (2014) may be considered a "what if" scenario, where it is not considered to which extent the bike-sharing system is substituting owned bikes in comparison with other transport 
means. Firnkorn et al. (2011) take a broader perspective and evaluate how introducing a car-sharing system substitutes three different transportation alternatives (public transportation, private car, borrowed car) and how the overall transport need changes. Changes in consumption practices and user needs are commonly known to lead to rebound effects, which is an issue frequently discussed in the PSS literature, see e.g. Goedkoop et al. (1999), Kuo and Wang (2012), Mont (2004b, p. 111), Tukker (2004) or Gottberg et al. (2010) as well as in LCA literature (Vivanco and Voet, 2014; Weidema et al., 2009). How the reference system is defined will influence the ability of the LCA to capture rebound effects.

Also related to the reference system are the substitutions when dealing with multiple life cycles. Even though PSS does not necessarily pay special attention to end-of-life aspects (Gelbmann and Hammerl, 2014), in many cases the PSS setup incentivises the provider to reuse or remanufacture the products (Mont, 2004b, p. 119) and "close the loop" in material use (Thurston and De La Torre, 2007), thereby extending the product's life into multiple life cycles (CH5). However, there is typically not a one-for-one trade-off between new goods and second-hand goods (Madsen, 2015; Thomas, 2003). So, for products that are remarketed into a new context it cannot automatically be assumed to substitute a new version of the same product. In fact, the product might substitute something very different or increase utility. Finding data and information on what is being substituted in subsequent life cycles for these types of studies is important for allocating impacts between life cycles and can be challenging. However, a suggested procedure is described in e.g. Ekvall and Weidema (2004) that focuses on identifying the products and the market segments that are affected by the remarketed products.

Considering whether the reference system can be fixed to one alternative or needs to be expanded to cover the whole contextual system is both depending on the study purpose and the type of PSS under consideration. As a consequence, considering the nature of the reference system might also lead to a change in study scope(s) selected. For "PSS optimization" the reference system will be the PSS itself and is thus relatively easily defined. In contrast, "PSS comparison" and "PSS consequences” deal with evaluating the effect of changing to a PSS solution and are by default of comparative nature. For "PSS comparison" the reference system can be defined as one or more predefined alternatives to which the PSS is compared. In these cases, the reference system will often be the traditional product-sales type business as demonstrated by Lindahl et al. (2014). When evaluating "PSS consequences”, understanding the complexity and capturing all relevant alternatives of a PSS would require a broader definition of the reference system, and focus will be on identifying and evaluating the actual substitutions. For traditional product alternatives such as cars and public transportation, studies on cross-price elasticity could indicate the degree in which one product substitutes another, as the studies evaluate how the demand for one product responds to the change of the price of another. In absence of adequate diffusion of PSS (Tukker, 2013), such studies are unlikely to exist for novel PSS solutions. For many practical business cases, however, the common methods to assess market shares for new products and/or services can be regarded as sufficient to assess these causal effects.

\subsection{Functional unit}

Compared to other techniques for environmental assessment, LCA is a relative approach based on a Functional Unit (FU) (ISO, 2006b). An appropriate definition of a FU is therefore a core task of any LCA. It provides the reference to which all other data in the assessment is normalised (Weidema et al., 2004). The FU especially plays an important role in comparison of alternative product systems. Once the FU is defined it is translated into quantifiable reference flow(s) to which all other input and output flows quantitatively relate (European Commission, 2010).

ISO (2006b) does not provide strict guidelines on how to structure the FU, but simply states that it should be clearly defined and measurable. Weidema et al. (2004) however, do provide such guidelines, but with a strong focus on tangible 
products and limited attention to how this might be different for services or complex systems. They recommend describing the product in terms of its obligatory, positioning and market-irrelevant properties and include the obligatory properties in the FU. The International Reference Life Cycle Data System (ILCD) Handbook proposes to define the FU by answering the following questions in the definition: “What?”, "How much?”, "How well?”, and "For how long?” and to use the division between obligatory and positioning properties wherever available (European Commission, 2010, p 63). In general, LCA guidelines emphasise the importance of anchoring the $\mathrm{FU}$ in terms of the function delivered by the product and not in terms of the product itself (e.g. rather "provide lighting" than "one lamp” (Rebitzer et al., 2004)). This is especially important to avoid any differences in functional output in comparative assessments. In this way, the system boundaries should be expanded to include alternative ways to provide the same function (Rebitzer et al., 2004).

Reap et al. (2008) also warn against defining the FU too strictly, due to the danger of reality not being well reflected, plus possible changes in customer preferences not being captured. At the same time they emphasise the importance of specifying and prioritizing sub-functions when defining the functional unit, referring to Cooper (2003). As PSS combine tangible and intangible elements (CH6), they often deliver a combination of sub-functions that cannot be separated. An example is a laundry service, where the clothes are washed, dried, packed and transported. Haapala et al. (2008) compare home-washing and a laundry service and state the functional unit as: "the annual volume of clothes needing laundering by 240 households". However, the assessment only includes the washing process (including production, use, and end-of-life of the washing machines) and the transportation process. Since a laundry service would not deliver wet clothes back to the customer, the drying process should be included in the assessment as well as the substituted drying behaviour when compared to homewashing. The authors acknowledge that the drying process might also affect the environmental impact and also state that a laundry service might package the clean clothes, which would not be done at home (Haapala et al., 2008). For PSS that include multiple functions, the FU should be supplemented with a description of these sub-functions and only when subfunctions are equivalent in the compared systems can they be argued to be left out of the assessment.

The fact that the FU definition can be challenging for PSS have also been addressed in the PSS literature (Brezet et al., 2001; Goedkoop et al., 1999; Vezzoli et al., 2014). For example Goedkoop et al. (1999) state that: "the result of a service cannot always be easily expressed in terms of a functional unit. Many services provide rather soft elements, which are not easy to catch in a measurable functional unit". This relates to the challenge of capturing the intangible value of PSS in evaluating their performance (Tukker, 2013). The fact that PSS affect user behaviour (CH2) and include intangible elements (CH6) makes it more difficult to ensure functional equivalence between alternatives.

In order to capture changes in user behaviour, it is argued that for PSS the FU should be defined broadly, which means e.g. going from comparing a passenger kilometre of a car with a passenger $\mathrm{km}$ of a train to "average transport behaviour during one year" (Goedkoop et al., 1999). This will avoid neglecting differences in performance such as that implied by the rebound effect (Weidema et al., 2009, p. 22). In both cases, the environmental impact of the passenger km of a car and a passenger $\mathrm{km}$ of a train would need to be assessed, but the wide definition allows for including behavioural aspects (how many km pr. year) and thereby account for the rebound effects. Furthermore, this wide definition also allows for including other transport modes. These would then, however, also need to be assessed, adding complexity to the study.

It has also been proposed to supplement or replace the functional unit with the economic value of the PSS. Goedkoop et al. (1999) used the so-called E2 vector to express the environmental impact in relation to the cumulative value creation over the life cycle. Vogtländer et al. (2002) use a similar approach in their eco-costs/value model, which has been applied to both products and PSS (Mestre and Vogtlander, 2013; Scheepens et al., 2015). The advantage of this approach especially lies during the design stage, where differences in value outcome can be mitigated in order to avoid rebound effects. These 
rebound effects occur when a product or PSS with lower environmental impact at the same time has a lower economic value, since when people save money they will spend them again (Scheepens et al., 2015), often leading to actual impact savings from an improvement being less than expected.

However, choosing a broad FU or expressing the FU in term of economic value does not change the fact that it is a matter of user preferences that determines what is comparable and what is not. For both "PSS comparison" and "PSS consequences" the LCA practitioner will need to determine which alternatives are relevant in the eyes of the user and how these affect the FU. Weidema (2003) suggests using quality specifications to delimit what can be regarded as similar products. In evaluating an existing system, information on user preferences can be used to determine which alternatives exists and thus how they are comparable. However, as also discussed in section 4.1, this information is not as available when LCA is used for early PSS design (CH4).

Even though stating that systems shall be compared using the same FU, ISO (2006b, p. 11) adds that any differences between parameters should be identified and reported, indicating that a qualitative description can be used to support a FU. Goedkoop et al. (1999) also emphasise listing all discrepancies that cannot be fully expressed in the FU.

To sum up, the challenge of defining the FU concerns two aspects: how broad or narrow the FU should be (e.g. total transport behaviour during one year or one single trip?) and how to ensure comparability of the chosen alternatives, including specifying sub-functions. In relation to the three study scopes, "PSS consequences” would employ a broad definition, in order to capture all system dependencies, while "PSS comparison" might choose a narrower definition with specific attention given to how the alternatives might differ in terms of performance. For "PSS optimization" there is no comparison to any distinct alternative, and the FU definition is less challenging as it can simply be defined as the function of the PSS.

\subsection{System boundary}

Once the functional output is established, the system boundary must be determined, including which processes to include and exclude (boundary selection and cut-off criteria) and where to use specific or generic data (ISO, 2006b).

In this process, a distinction between foreground and background systems is often made. Adopting the management perspective (European Commission, 2010, p. 96), processes in the foreground system are those within management of the PSS provider (either as single operator or as a network), while processes in the background processes are those operated as part of the system but that are not under his direct control or decisive influence. While processes in the foreground system typically use primary inventory data, processes in the background system often use secondary inventory data e.g. from LCA databases. The fact that PSS is often a design strategy ( $\mathrm{CH} 4)$ can challenge the data gathering, since data availability will be limited. A scenario approach will be necessary in order to account for assumptions. This will also lead to the use of more secondary data e.g. from LCA databases in the life cycle inventory (LCI) phase.

In general, three types of LCIs can be distinguished: Process-LCI; Input-Output-LCI; and Hybrid-LCI, where the latter combines Process- and Input-Output-based data (Suh and Huppes, 2005). A process-based LCA gathers data in a bottom-up approach, and for these assessments, setting appropriate system boundaries between significant and insignificant processes is a common challenge. Ideally, the processes that are left out in a process-based LCA should have an insignificant contribution to the results, but this may not always be true (Finnveden et al., 2009). For PSS, this becomes even more pronounced, because of the fact that a PSS is a system of products and services (CH6) and often relies on supporting products and services (CH7) such as infrastructure, transportation, maintenance programmes and administration. Even though it has been proven that a shift from material-intensive industries to less material-intensive services reduces the greenhouse gases emission 
intensity per Gross Domestic Product (GDP), services still have significant impacts, since they are ultimately anchored to manufacturing outputs (Suh, 2006). Thus, for many service providers, a large share of their environmental loads are not produced at the actual site of activity but are indirect impacts (Junnila, 2008); one might say that the significant processes are part of the background system. Thus, while a service by itself might have very limited environmental impacts, including the products and services upon which they depend becomes vital (Brezet 2001). While traditional process LCA often fail at addressing services sufficiently (Lenzen, 2001), Environmental Input Output (EIO) LCA has been used to address this issue and together with hybrid approaches the method is proposed as a prominent means to avoid critical cut offs also known as truncation errors (Reap et al., 2008; Suh et al., 2004; Weidema et al., 2009). Junnila (2008) use EIO LCA on service industries and demonstrates that the environmental impact increases with $50-70 \%$ compared to process LCA. Roughly $50 \%$ of the difference is caused by the differences in purchased services (Junnila, 2008). Kjaer et al. (2015) demonstrate that the use of financial data as a starting point for a comprehensive analysis of complex systems is feasible through an EIO approach. Also, in the MePSS (Methodology for PSS) project's list of tools, EIO LCA is proposed for analysing or comparing PSS ('MEPSS - Webtool', 2004).

However, EIO-based LCA also suffers from limitations depending on the EIO model used (Kjaer et al., 2015), with the most pronounced limitation being sector aggregation which result in a higher level of uncertainty in the source data compared to process LCA (Suh and Huppes, 2005). For assessments of PSS, hybrid approaches will most likely be needed, which can be both time consuming and needs expertise.

Also relevant for the system boundaries is how co-products are treated during the LCI phase in cases of multi-functional processes. ISO (2006b) recommends avoiding allocation and use sub-division or system expansion, also in situations of reuse and recycling, which is often relevant for PSS (CH5). However, allocation is often used in LCA and is one of the most discussed methodological issues in LCA (Finnveden et al., 2009).

To sum up, for PSS, the complexity of the system (often a combination of multiple product and service elements) (CH6), the reliance on supporting products and services in the background system (CH7) and potential extensions to multiple life cycles (CH5) introduces a risk of significant processes to be either neglected or assessed with greater inaccuracy, which adds to the uncertainty of the results.

For all three study scopes, the challenge is about ensuring a sufficient level of completeness in system boundaries and avoiding truncation errors, leaving out potentially important contributing processes. For "PSS Comparison" and "PSS Consequences" this is complicated further, when ensuring the same level of completeness in system boundaries when comparing radically different systems (CH1). This should be solved by applying a cut-off criterion as close to zero as possible and being consistent when using LCA databases as secondary data sources.

\section{Discussion and conclusions}

In this article, the following aspects were found challenging when using LCA to evaluate the environmental performance of PSS:

1) The assessment evaluates the effect of a (sometimes radical) change ( $\mathrm{CH} 1)$, where user behaviour and perceived value is affected (CH2). Its success depend on contextual factors (CH3), and knowledge about the system is often limited (CH4). These factors make it challenging to define an appropriate reference system, ensure functional equivalence in the FU definition and handle the uncertainties and dynamic nature of the assessment. Furthermore, PSS often pursue 
product lifetime extensions through multiple life cycles (CH5), thereby challenging the reference system, which needs to be determined in order to allocate impacts between life cycles.

2) The complexity of the system (many elements/flows) (CH6) and its reliance on supporting systems (CH7) challenge the system boundaries, with completeness and consistency between the compared systems as main areas of concern.

The identified challenges are pronounced for PSS but cannot be claimed to be limited to PSS. They can apply to tangible products as well, especially when dealing with innovative consumer products such as multifunctional smartphones or disruptive technologies, where an LCA also has to deal with issues such as radical contextual and behavioural changes and limited data availability (see e.g. Miller and Keoleian (2015) on transformative technologies).

Our review of LCA guidelines found that the identified challenges are implicitly addressed and with no specific attention given to solutions that consist of both tangible and intangible elements and involves behavioural changes such as PSS. While solutions to these challenges have been sporadically proposed, they are not common LCA practice, and their implementation for PSS has remained unexplored.

It is acknowledged that further work on a more comprehensive guidance would be beneficial in the field of non-technical functions and related studies (European Commission, 2010, p. 67), which in our perspective also cover PSS. We acknowledge the fact that using LCA methodology to evaluate PSS should adopt a broad LCA perspective and that further guidelines for doing so should be developed. We recommend that specific attention should be given to the goal and scope definition with elaborated guidelines for choosing the appropriate scope depending on the study goal and characteristic of the PSS under consideration. In this paper, we defined three study scopes, in order to distinguish between whether the assessment has the purpose of supporting PSS design optimization; to compare two or more alternatives; or to evaluate the consequences of implementing a PSS from a broader perspective. Table 4 provides an overview of how the identified challenges relate to the three scopes and presents overall recommendations derived from the research.

\begin{tabular}{|c|c|c|c|}
\hline Study scope & Reference system & Function unit & System boundaries \\
\hline PSS optimization & $\begin{array}{l}\text { The reference system is the existing } \\
\text { PSS. }\end{array}$ & $\begin{array}{l}\text { Can be defined as the function of the } \\
\text { PSS. }\end{array}$ & $\begin{array}{l}\text { All contributing flows including } \\
\text { processes in the background system } \\
\text { should be included in the assessment in } \\
\text { order to identify all relevant hotspots } \\
\text { and ensure completeness in boundary } \\
\text { selection. }\end{array}$ \\
\hline PSS comparison & $\begin{array}{l}\text { The reference system is the comparable } \\
\text { alternative(s). }\end{array}$ & $\begin{array}{l}\text { Equivalence between compared systems } \\
\text { needs to be ensured in terms of } \\
\text { functionality (including specifying sub- } \\
\text { functions) and quality. Discrepancies in } \\
\text { perceived value should be listed and } \\
\text { evaluated in regards to potential } \\
\text { rebound effects. }\end{array}$ & $\begin{array}{l}\text { Same as "PSS optimization,” however } \\
\text { concerns about level of completeness } \\
\text { expand to also cover the compared } \\
\text { systems. }\end{array}$ \\
\hline PSS consequences & $\begin{array}{l}\text { The reference system is the baseline } \\
\text { situation without the PSS. }\end{array}$ & $\begin{array}{l}\text { Same as PSS comparison, together with } \\
\text { a broader definition of the FU that } \\
\text { allows inclusion of all relevant } \\
\text { substitutes as well as behavioural } \\
\text { changes and changes in other affected } \\
\text { systems. }\end{array}$ & Same as “PSS comparison”. \\
\hline
\end{tabular}

Table 4: The challenges related to the three study scope

For studies evaluating the changes caused by the PSS, specific attention should be given to describing the reference system and if it can be fixed to one comparable alternative or needs expansion towards multiple systems, in order to capture all relevant changes and rebound effects. The FU should be defined accordingly and functional equivalence should be matched by composing the reference system of existing products and services and any discrepancies should be listed as 
suggested by Goedkoop et al. (1999). Guidelines should emphasise the importance of including processes in the background system, since these often comprise a large share of the environmental impacts caused by services. Furthermore, the dynamic nature of PSS should be addressed, and more advanced tools such as Causal Loop Diagrams together with system dynamics (Laurenti et al., 2014; Lee et al., 2012), and simulation tools (Komoto et al., 2005; Phumbua and Tjahjono, 2012) can be used in order to capture dynamic behaviour in PSS.

Despite the identified challenges, we believe that LCA is applicable to PSS. However, the appropriateness of an LCA approach, which is based on a single functional unit, and is fully comparable between systems, has been challenged by some authors. Instead of using a FU, Lagerstedt et al., (2003) suggest reporting all functional qualities provided by the system in a systematized way, and provide a visualization of similarities and differences for both eco-profiles and functional qualities. Another suggestion is to use satisfaction units to express the FU (Vezzoli et al., 2014) or use "customer perceived value” instead of "functionality" as a basis for evaluation (Mestre and Vogtlander, 2013) as discussed in section 4.2. A solution might be to follow the notion in Finnveden et al. (2009) and use the term "environmental systems analysis using LCA methodology" instead of an LCA when evaluating the environmental performance of complex systems such as PSS. We suggest that by taking this broader perspective, environmental evaluations could benefit from using LCA methodology, while allowing for the necessary broad definition of the functional unit. It would allow for the necessary scenario approach to account for complex reference systems and data uncertainty. Furthermore, an assessment of differences in value outcome between the compared systems could help capture and/or mitigate rebound effects. Note, that we here use the term value outcome and not economic value to highlight that not only money but also differences in time, space, technology, access, etc. may lead to behavioural changes, which can introduce rebound effects.

A limitation of the current study is that no connection is made between the broad spectrum of different types of PSS and the identified characteristics and challenges. PSS can be classified according to different dimensions. One dimension is the business model. For example, it could be argued that for product-oriented and result-oriented PSS, the reference system is more clear and easier to control than use-oriented PSS, where the solution is provided as a platform to the users and products might be used less carefully and be discharged of earlier compared to owned products (Tukker, 2013). A second dimension is whether a PSS is in a B2B or B2C context, which is important because the intangible value of owning products is stronger for private consumers (Kang and Wimmer, 2008; Sakao et al., 2009; Tukker, 2013), and can influence user acceptance. Thirdly, there is a difference between whether an analysis is done ex-ante or ex-post in terms of the uncertainty, since ex-ante assessments will be based on estimates rather than verified data. Knowledge of the system under analysis is much stronger when the analysis is done post-implementation; however it is in the design process that most radical changes can be proposed (Lagerstedt et al., 2003). More work is needed considering how these and other dimensions could be used to categorise PSS in order to guide which aspects and methodological choices to consider in the environmental evaluation. Finally, one could consider the different life cycle profiles of the system (Goedkoop et al., 1999) and the environmental strategy that the PSS promotes. For example, for systems where the highest environmental impacts occur in the use-stage, such as most transport options or other energy-consuming systems, the PSS should focus on environmental strategies addressing this. In this regard, a challenge not addressed in this article is the importance of capturing potential trade-offs between life cycle stages or between impact categories when introducing a PSS.

It has been commonly accepted that PSS is not the sustainability panacea (Mont, 2004b; Tukker, 2013) and examples have shown that it is not necessarily the PSS business model that determines whether environmental gains are received or not (Agrawal et al., 2012; Tasaki et al., 2006). As mentioned, future work includes better guidelines for environmental evaluation of PSS. Also, addition cases of LCA methodology being used to evaluate the environmental performance of PSS are called 
for and especially studies trying to capture the consequences of introducing a PSS into a system is needed, in order to argue which criteria needs to be in place for ensuring true environmental benefits. Such case studies may assist in identifying methodological challenges and ways to overcome them and thereby support the development of the LCA method.

\section{Acknowledgements}

The authors would like to thank the TORM Foundation for its financial support. We would also like to acknowledge the support from PSS and LCA experts for their comments and suggestions when deriving and validating the study results. 


\section{References}

Agrawal, V. V., Ferguson, M., Toktay, L.B., Thomas, V.M., 2012. Is Leasing Greener Than Selling? Manage. Sci. 58, 523533.

Amaya, J., Lelah, A., Zwolinski, P., 2014. Design for intensified use in product-service systems using life-cycle analysis. J. Eng. Des. 25, 1-23.

Anttonen, M., Halme, M., Houtbeckers, E., Nurkka, J., 2013. The other side of sustainable innovation: Is there a demand for innovative services? J. Clean. Prod. 45, 89-103.

Baines, T.S., Lightfoot, H.W., Evans, S.., Neely, A.., Greenough, R.., Peppard, J.., Roy, R.., Shehab, E.., Braganza, A.., Tiwari, A.., Alcock, J.R., Angus, J.P., Bastl, M., Cousens, A.., Irving, P.., Johnson, M.., Kingston, J.., Lockett, H.., Martinez, V.., Michele, P.., Tranfield, D.., Walton, I.M., Wilson, H.., 2007. State-of-the-art in product-service systems. Proc. Inst. Mech. Eng. Part B J. Eng. Manuf. 221, 1543-1552.

Bennett, E.B., Graedel, T.E., 2000. ‘Conditioned Air’: Evaluating an Environmentally Preferable Service. Environ. Sci. Technol. 34, 541-545.

Beuren, F.H., Gomes Ferreira, M.G., Cauchick Miguel, P.A., 2013. Product-service systems: a literature review on integrated products and services. J. Clean. Prod. 47, 222-231.

Bey, N., McAloone, T.C., 2006. From LCA to PSS - Making leaps towards sustainability by applying product / servicesystem thinking in product development, in: 13th CIRP International Conference on Life Cycle Engineering. pp. 571576.

Biolchini, J., Mian, P.G., Natali, A.C.C., Travassos, G.H., 2005. Systematic Review in Software Engineering, Technical Report ES 679/05. Rio de Janeiro.

Bocken, N.M.P., Short, S.W., Rana, P., Evans, S., 2014. A literature and practice review to develop sustainable business model archetypes. J. Clean. Prod. 65, 42-56.

Brezet, J., Bijma, A., Ehrenfeld, J., Silvester, S., 2001. The design of eco-efficient services - Method, tools and review of the case study based 'Designing Eco-efficient Services’ project. Delft, The Netherlands.

Büttner, J., Mlasowsky, H., Birkholz, T., et al., 2011. Optimising Bike Sharing in European Cities - a Handbook.

Ceschin, F., 2013. Critical factors for implementing and diffusing sustainable product-Service systems: Insights from innovation studies and companies’ experiences. J. Clean. Prod. 45, 74-88.

Cooper, J.S., 2003. Specifying functional units and reference flows for comparable alternatives. Int. J. Life Cycle Assess. 8, 337-349.

Ekvall, T., Weidema, B.P., 2004. System boundaries and input data in consequential life cycle inventory analysis. Int. J. Life Cycle Assess. 9, 161-171.

European Commission, 2010. International Reference Life Cycle Data System (ILCD) Handbook - General guide for Life Cycle Assessment - Detailed guidance, First edit. ed. Publication Office of the European Union, Luxembourg.

Evans, S., Partidário, P.J., Lambert, J., 2007. Industrialization as a key element of sustainable product-service solutions. Int. J. Prod. Res. 45, 4225-4246.

Finnveden, G., Hauschild, M.Z., Ekvall, T., Guinée, J., Heijungs, R., Hellweg, S., Koehler, A., Pennington, D., Suh, S., 2009. Recent developments in Life Cycle Assessment. J. Environ. Manage. 91, 1-21.

Firnkorn, J.J., Müller, M., 2011. What will be the environmental effects of new free-floating car-sharing systems? The case of car2go in Ulm. Ecol. Econ. 70, 1519-1528.

Gelbmann, U., Hammerl, B., 2014. Integrative re-use systems as innovative business models for devising sustainable product-service-systems. J. Clean. Prod. 97, 50-60.

Goedkoop, M.J., van Halen, C.J.G., te Riele, H.R.M., Rommens, P.J.M., 1999. Product service systems, ecological and economic basics, Report for Dutch Ministries of Environment (VROM) and Economic Affairs (EZ). Amersfoort, The Netherlands.

Gottberg, A., Longhurst, P.J., Cook, M.B., 2010. Exploring the potential of Product Service Systems to achieve household waste prevention on new housing developments in the UK. Waste Manag. Res. 28, 228-235.

Hirschl, B., Konrad, W., Scholl, G., 2003. New concepts in product use for sustainable consumption. J. Clean. Prod. 11, 873881. 
Haapala, K.R., Brown, K.L., Sutherland, J.W., 2008. A life cycle environmental and economic comparison of clothes washing product-service systems, in: Transactions of the North American Manufacturing Research Institution of SME. Monterrey; Mexico, pp. 333-340.

ISO, 2006a. ISO 14040 International Standard, Environmental management - Life cycle assessment - Principles and framework. International Organisation for Standardization, Geneva, Switzerland.

ISO, 2006b. ISO 14044 International Standard, Environmental management - Life cycle assessment - Requirements and guidelines. International Organisation for Standardization, Geneva, Switzerland.

Joore, P., Brezet, H., 2014. A Multilevel Design Model: the mutual relationship between product-service system development and societal change processes. J. Clean. Prod. 97, 92-105.

Junnila, S., 2008. Life cycle management of energy-consuming products in companies using IO-LCA. Int. J. Life Cycle Assess. 13, 432-439.

Kang, M.-J., Wimmer, R., 2008. Product service systems as systemic cures for obese consumption and production. J. Clean. Prod. 16, 1146-1152.

Kerr, W., Ryan, C., 2001. Eco-efficiency gains from remanufacturing: A case study of photocopier remanufacturing at Fuji Xerox Australia. J. Clean. Prod. 9, 75-81.

Kjaer, L., Høst-Madsen, N., Schmidt, J., McAloone, T., 2015. Application of Environmental Input-Output Analysis for Corporate and Product Environmental Footprints-Learnings from Three Cases. Sustainability 7, 11438-11461.

Klöpffer, W., 2014. Background and Future Prospects in Life Cycle Assessment, LCA Compendium - The Complete World of Life Cycle Assessment. Springer Dordrecht Heidelberg New York London, Frankfurt am Main, Germany.

Komoto, H., Tomiyama, T., Nagel, M., Silvester, S., Brezet, H., 2005. Life Cycle Simulation for Analyzing Product Service Systems, in: Fourth International Symposium on Environmentally Conscious Design and Inverse Manufacturing, Eco Design 2005. pp. 386-393.

Kuo, T.C., Wang, M.L., 2012. The optimisation of maintenance service levels to support the product service system. Int. J. Prod. Res. 50, 6691-6708.

Lagerstedt, J., Luttropp, C., Lindfors, L.G., 2003. Functional priorities in LCA and design for environment. Int. J. Life Cycle Assess. 8, 160-166.

Laurenti, R., Lazarevic, D., Poulikidou, S., Montrucchio, V., Bistagnino, L., Frostell, B., 2014. Group Model-Building to identify potential sources of environmental impacts outside the scope of LCA studies. J. Clean. Prod. 72, 96-109.

Lee, S., Geum, Y., Lee, H., Park, Y., 2012. Dynamic and multidimensional measurement of product-service system (PSS) sustainability: A triple bottom line (TBL)-based system dynamics approach. J. Clean. Prod. 32, $173-182$.

Lelah, A., Mathieux, F., Brissaud, D., 2011. Contributions to eco-design of machine-to-machine product service systems: the example of waste glass collection. J. Clean. Prod. 19, 1033-1044.

Lenzen, M., 2001. Errors in Conventional and Input-Output-based Life-Cycle Inventories.pdf. J. Ind. Ecol. 4, $127-148$.

Lindahl, M., Sundin, E., Sakao, T., 2014. Environmental and economic benefits of Integrated Product Service Offerings quantified with real business cases. J. Clean. Prod. 64, 288-296.

Madsen, M.B., 2015. Deleøkonomiens klimapotentiale. CONCITO, Copenhagen, Denmark.

Manzini, E., Vezzoli, C., 2002. Product-Service Systems and Sustainability - Opportunities for sustainable solutions. UNEP (United Nations Environment Programme), Paris, France.

Manzini, E., Vezzoli, C., 2003. A strategic design approach to develop sustainable product service systems: Examples taken from the ‘environmentally friendly innovation’ Italian prize. J. Clean. Prod. 11, 851-857.

Meier, H., Roy, R., Seliger, G., 2010. Industrial Product-Service systems-IPS2. CIRP Ann. - Manuf. Technol. 59, $607-627$.

MEPSS - Webtool [WWW Document], 2004. . Screen. LCA using input output. URL http://www.mepss.nl/index.php?p=tool\&l4=W12 (accessed 5.26.15).

Mestre, A., Vogtlander, J., 2013. Eco-efficient value creation of cork products: An LCA-based method for design intervention. J. Clean. Prod. 57, 101-114.

Miller, S. a, Keoleian, G. a, 2015. Framework for analyzing transformative technologies in life cycle assessment. Environ. Sci. Technol. 49, 3067-75.

Mont, O., 2004a. Reducing life-cycle environmental impacts through systems of joint use. Greener Manag. Int. 45, 63-77. 
Mont, O., 2004b. Product service systems: panacea or myth? Dissertation. Lund University.

Phumbua, S., Tjahjono, B., 2012. Towards product-service systems modelling: a quest for dynamic behaviour and model parameters. Int. J. Prod. Res. 50, 425-442.

Reap, J., Roman, F., Duncan, S., Bras, B., 2008. A survey of unresolved problems in life cycle assessment part 2. Int. J. Life Cycle Assess. 13, 374-388.

Rebitzer, G., Ekvall, T., Frischknecht, R., Hunkeler, D., Norris, G., Rydberg, T., Schmidt, W.P., Suh, S., Weidema, B.P., Pennington, D.W., 2004. Life cycle assessment Part 1: Framework, goal and scope definition, inventory analysis, and applications. Environ. Int. 30, 701-720.

Reim, W., Parida, V., Örtqvist, D., 2014. Product-Service Systems (PSS) business models and tactics - a systematic literature review. J. Clean. Prod. 97, 61-75.

Rexfelt, O., Ornäs, V.H.A., 2009. Consumer acceptance of product-service systems: Designing for relative advantages and uncertainty reductions. J. Manuf. Technol. Manag. 20, 674-699.

Sakao, T., Sandström, G.Ö., Matzen, D., 2009. Framing research for service orientation of manufacturers through PSS approaches. J. Manuf. Technol. Manag. 20, 754-778.

Salazar, C., Lelah, A., Brissaud, D., 2014. Eco-designing Product Service Systems by degrading functions while maintaining user satisfaction. J. Clean. Prod. 87, 452-462.

Scheepens, a. E., Vogtländer, J.G., Brezet, J.C., 2015. Two life cycle assessment (LCA) based methods to analyse and design complex (regional) circular economy systems. Case: making water tourism more sustainable. J. Clean. Prod. 112.

Shih, L.H., Chou, T.Y., 2011. Customer concerns about uncertainty and willingness to pay in leasing solar power systems. Int. J. Environ. Sci. Technol. 8, 523-532.

Sonnemann, G., Vigon, B., 2011. Global Guidance Principles For Life Cycle Assessment Databases - A Basis for Greener Processes and Products. UNEP-SETAC Life Cycle Initiative. Paris.

Suh, S., 2006. Are services better for climate change? Environ. Sci. Technol. 40, 6555-60.

Suh, S., Huppes, G., 2005. Methods for Life Cycle Inventory of a product. J. Clean. Prod. 13, 687-697.

Suh, S., Lenzen, M., Treloar, G.J., Hondo, H., Horvath, A., Huppes, G., Jolliet, O., Klann, U., Krewitt, W., Moriguchi, Y., Munksgaard, J., Norris, G., 2004. System boundary selection in life-cycle inventories using hybrid approaches. Environ. Sci. Technol. 38, 657-664.

Tan, A.R., Matzen, D., McAloone, T.C., Evans, S., 2010. Strategies for designing and developing services for manufacturing firms. CIRP J. Manuf. Sci. Technol. 3, 90-97.

Tan, A.R., McAloone, T.C., 2006. Characteristics of strategies in product/service-system development, in: 9th International Design Conference, DESIGN 2006. Dubrovnik, pp. 1435-1442.

Tasaki, T., Hashimoto, S., Moriguchi, Y., 2006. A quantitative method to evaluate the level of material use in lease/reuse systems of electrical and electronic equipment. J. Clean. Prod. 14, 1519-1528.

Thomas, V.M., 2003. Demand and Dematerialization Impacts of Second-Hand Markets - Reuse or More Use? J. Ind. Ecol. 7, 65-78.

Thurston, D.L., De La Torre, J.P., 2007. Leasing and extended producer responsibility for personal computer component reuse. Int. J. Environ. Pollut. 29, 104-126.

Tukker, A., 2004. Eight types of product-service system: eight ways to sustainability? Experiences from SusProNet. Bus. Strateg. Environ. 13, 246-260.

Tukker, A., 2013. Product services for a resource-efficient and circular economy - a review. J. Clean. Prod. 97, 76-91.

Tukker, A., Tischner, U., 2006. Product-services as a research field: past, present and future. Reflections from a decade of research. J. Clean. Prod. 14, 1552-1556.

Vezzoli, C., Ceschin, F., Diehl, J.C., Kohtala, C., 2015. New Design Challenges to Widely Implement 'Sustainable ProductService Systems’. J. Clean. Prod. 97, 1-12.

Vezzoli, C., Kohtala, C., Srinivasan, A., 2014. Product-Service System Design for Sustainability. Greenleaf Publishing Limited Aizlewood's.

Vivanco, D.F., Voet, E. Van Der, 2014. The rebound effect through industrial ecology's eyes : a review of LCA-based studies. Int. J. Life Cycle Assess. 1933-1947. 
Vogtländer, J.G., Bijma, A., Brezet, H.C., 2002. Communicating the eco-efficiency of products and services by means of the eco-costs/value model. J. Clean. Prod. 10, 57-67.

Wang, P.P., Ming, X.G., Li, D., Kong, F.B., Wang, L., Wu, Z.Y., 2011. Status review and research strategies on productservice systems. Int. J. Prod. Res. 49, 6863-6883.

Weidema, B., 2003. Market information in life cycle assessment, Environmental Project No. 863. Danish Environmental Protection Agency, Copenhagen, Denmark.

Weidema, B., Wenzel, H., Petersen, C., Hansen, K., 2004. The Product, Functional Unit and Reference Flows in LCA, Environmental News No. 70. Danish Ministry of the Environment, Environmental Protection Agency.

Weidema, B.P., Ekvall, T., Heijungs, R., 2009. Guidelines for application of deepened and broadened LCA, Deliverable D18 of work package 5 of the CALCAS project. 